\title{
SGLT-1-mediated glucose uptake protects human intestinal epithelial cells against Giardia duodenalis-induced apoptosis
}

\author{
Linda C.H. Yua,b, Ching-ying Huang ${ }^{b}$, Wei-ting Kuo ${ }^{b}$, Heather Sayer ${ }^{a}$, Jerrold R. Turner ${ }^{c}$, and \\ Andre G. Buret ${ }^{a}$ \\ aDepartment of Biological Sciences, BI 117, Inflammation Research Network, University of Calgary, 2500 \\ University Dr. N.W., Calgary, AB, Canada T2N 1N4 \\ bGraduate Institute of Physiology, National Taiwan University College of Medicine, Taipei, Taiwan, ROC \\ cDepartment of Pathology, University of Chicago, Chicago, IL, USA
}

\begin{abstract}
Infection with Giardia duodenalis is one of the most common causes of waterborne diarrheal disease worldwide. Mechanisms of pathogenesis and host response in giardiasis remain incompletely understood. Previous studies have shown that exposure to G. duodenalis products induce apoptosis in enterocytes. We recently discovered that sodium-dependent glucose cotransporter (SGLT)-1mediated glucose uptake modulates enterocytic cell death induced by bacterial lipopolysaccharide. The aim of this study was to examine whether enhanced epithelial SGLT-1 activity may constitute a novel mechanism of host defense against $G$. duodenalis-induced apoptosis. SGLT-1-transfected Caco- 2 cells were exposed to G. duodenalis products in low $(5 \mathrm{mM})$ or high $(25 \mathrm{mM})$ glucose media. In low glucose environments, G. duodenalis-induced caspase-3 activation and DNA fragmentation in these cells. These apoptotic phenomena were abolished in the presence of high glucose. A soluble proteolytic fraction of G. duodenalis was found to upregulate SGLT-1-mediated glucose uptake in a dose- and time-dependent manner, in association with increased apical SGLT-1 expression on epithelial cells. Kinetic analysis showed that this phenomenon resulted from an increase in the maximal rate of sugar transport $\left(V_{\max }\right)$ by SGLT-1, with no change in the affinity constant $\left(K_{\mathrm{m}}\right)$. The addition of phloridzin (a competitive inhibitor for glucose binding to SGLT-1) abolished the antiapoptotic effects exerted by high glucose. Together, the findings indicate that SGLT-1-dependent glucose uptake may represent a novel epithelial cell rescue mechanism against $G$. duodenalis-induced apoptosis.
\end{abstract}

\section{Keywords}

Giardia duodenalis; Enterocytes; Apoptosis; SGLT-1; Glucose; Cytoprotection

\section{Introduction}

The protozoan parasite, Giardia duodenalis (syn. Giardia lamblia, Giardia intestinalis) is one of the most frequently identified etiologic agents of waterborne intestinal disease worldwide ([Slifko et al., 2000] and [Savioli et al., 2006]). Giardia trophozoites mostly colonize the upper small intestine and adhere to the apical surface of the epithelium. Symptoms due to this infection are characterized by acute or chronic diarrhea, dehydration, abdominal cramping and weight loss. Studies in human patients, in experimental animal models, or in cell culture systems, have established that the infection causes small intestinal structural and functional abnormalities. These may include apoptosis induced epithelial barrier defects, microvillous shortening, disaccharidase deficiencies, hypersecretion of chloride, as well as malabsorption 
of electrolytes and water associated with infiltration of intraepithelial lymphocytes ([Belosevic et al., 1989], [Buret et al., 1992], [Scott et al., 2000], [Scott et al., 2002], [Scott et al., 2004], [Troeger et al., 2007] and [Panaro et al., 2007]).

In the intestine, enterocytes connected by tight junctions serve as the first line of defense against the influx of harmful luminal contents such as microbial pathogens and cytotoxic products. Physiological extrusion of senescent apoptotic enterocytes does not compromise intestinal barrier function ([Madara, 1990] and [Watson et al., 2005]). In contrast, exposure to enteric pathogens such as G. duodenalis, Escherichia coli, Salmonella enteritica or Helicobacter pylori induces excessive enterocytic apoptosis, which may adversely affect epithelial tight junctional integrity ([Jones et al., 2000], [Le'Negrate et al., 2001], [Chin et al., 2002], [Paesold et al., 2002], [Scott et al., 2002], [Yu et al., 2005], [Troeger et al., 2007] and [Panaro et al., 2007]). High concentrations of bacterial lipopolysaccharide (LPS) may also increase epithelial apoptosis and intestinal permeability ([Yu et al., 2005], [Yu et al., 2006] and [Chin et al., 2006]). While it has been established that $G$. duodenalis-induced intestinal permeability defects require caspase-3 activation and appear to be strain-dependent ([Teoh et al., 2000] and [Chin et al., 2002]), the mechanisms responsible for $G$. duodenalis-induced epithelial apoptosis remain incompletely understood.

Cytoprotective mechanisms evolved by host cells represent the cornerstone of homeostasis and cell survival upon exposure to exogenous pathological pro-apoptotic stimuli. Glucosemediated cytoprotection has been documented in a number of cell types, including myocardiocytes, vascular smooth muscle cells, mast cells, T cells and, most recently, in enterocytes ([Schaffer et al., 2000], [Hall et al., 2001], [Malhotra et al., 2001] and [Yu et al., 2005]). The mechanisms regulating this response remain poorly understood. The main apical transporter for active glucose uptake in intestinal epithelial cells is the sodium-dependent glucose co-transporter (SGLT)-1 (Hediger et al., 1987). SGLT-1 unidirectionally mediates glucose absorption from the intestinal lumen into epithelial cells. The basolateral transporter GLUT-2 facilitates diffusive transport of intracellular glucose into the interstitium and towards the bloodstream (Kimmich and Randles, 1981). Moreover, SGLT-1 co-transports glucose and sodium, which drives passive water uptake. This characteristic has been used for the development of oral rehydration therapy (ORT) to promote electrolyte balance, and manage hypersecretory diarrheal disease (Kimmich and Randles, 1984). Recent observations have described a novel cell rescue mechanism against LPS-induced apoptosis via SGLT-1 activation and enhanced glucose uptake into enterocytes ([Yu et al., 2005] and [Yu et al., 2006]). Whether this SGLT-1-mediated phenomenon confers cytoprotection against $G$. duodenalis-induced cellular apoptosis has yet to be explored.

The present study: (i) tested the hypothesis that high external glucose concentrations may protect human intestinal epithelial cells against apoptotic death caused by G. duodenalis; (ii) assessed the role of SGLT-1 as the glucose transporter responsible for the anti-apoptotic effect; and (iii) investigated the mechanism of G. duodenalis-induced SGLT-1 activation in these cells.

\section{Materials and methods}

\subsection{Cell culture model}

Human colonic Caco-2 cells transfected with native intestinal SGLT-1 (Turner et al., 1996) were grown in DMEM (Life technologies, Inc., Gaithersburg, MD) that contained $25 \mathrm{mM}$ of glucose as previously described ([Yu et al., 2005] and [Yu et al., 2006]). The media was supplemented with 10\% FBS, $15 \mathrm{mM}$ Hepes, $100 \mathrm{U} / \mathrm{ml}$ Penicillin, $0.1 \mathrm{mg} / \mathrm{ml}$ Streptomycin (Sigma, St. Louis, MO) and $0.25 \mathrm{mg} / \mathrm{ml}$ Geneticin (Life technologies, Inc.) (Turner et al., 1996). None of the polarized intestinal epithelial cell lines available today express detectable 
levels of transepithelial $\mathrm{Na}^{+}$-dependent glucose transport, which has been attributed to a deficiency of surface expression of SGLT-1 ([Turner et al., 1996] and [Kipp et al., 2003]). In these transfected cells, the expression of SGLT-1 protein on the apical membrane is associated with functional $\mathrm{Na}^{+}$-dependent uptake of glucose, and physiological transduction pathways in response to SGLT-1 activation ([Turner et al., 1996], [Shiue et al., 2005] and [Hu et al., 2006]). These cells were seeded in 8 -well chamber slides $\left(4 \times 10^{5}\right.$ cells/well; Lab-Tek, Nalge Nunc, Rochester, NY), 24-well plates ( $10^{6}$ cells/well; Costar, Corning Inc., Corning, NY), 6well plates $\left(6 \times 10^{6}\right.$ cells/well, Costar $)$ and 12 -well transwells, which contained $1 \mathrm{~cm}^{2}$ semipermeable filter membrane with $0.4 \mu \mathrm{m}$ pores $\left(10^{6} \mathrm{cells} / \mathrm{well}\right.$, Costar) and grown to confluency for 1 week at $37{ }^{\circ} \mathrm{C}$ with $5 \% \mathrm{CO}_{2}$ and $96 \%$ humidity for experiments. In all studies, cells were used between passages 21 and 27 .

\subsection{Giardia products}

Giardia duodenalis strain NF was obtained from an epidemic outbreak of human giardiasis in Newfoundland, Canada (Chin et al., 2002). Giardia duodenalis trophozoites were grown axenically at $37^{\circ} \mathrm{C}$ in Diamond's TYI-S33 media supplemented with piperacillin (Piprecil; Wyeth-Ayerst Canada Inc., Montreal, Que., Canada) in $15 \mathrm{ml}$ polystyrene centrifuge tubes (Falcon, Becton-Dickinson and Co., Franklin Lakes, NJ) and sub-cultured every 7 days to maintain the line. Recent studies have demonstrated that live trophozoites, parasite sonicates, and spent growth media of $G$. duodenalis induce cell apoptosis and barrier defects in Caco-2 and SCBN epithelial cell lines ([Teoh et al., 2000] and [Chin et al., 2002]). For the purpose of using a reproducible stimulus, and in order to circumvent the physical interference of whole live parasites with the sugar uptake assay, $G$. duodenalis sonicates were used as the challenge in the current study. To harvest live G. duodenalis trophozoites, media and dead parasites were removed by aspiration and the tubes were filled with sterile PBS. The live trophozoites were harvested at $\log$ phase $(48 \mathrm{~h}$ ) by cold shock on ice for $20 \mathrm{~min}$ followed by centrifugation at $500 \mathrm{~g}$ for $10 \mathrm{~min}$ at $4{ }^{\circ} \mathrm{C}$. The pellet was washed once with $4{ }^{\circ} \mathrm{C}$ PBS and the number of trophozoites was counted using a hemocytometer. Giardia duodenalis trophozoites were then resuspended and adjusted to $2 \times 10^{7}$ trophozoites $/ \mathrm{ml}$ in high or low glucose DMEM media (see below). Trophozoite suspensions were disrupted (550 Versonic Dismembrator, Fisher Scientific, Pittsburgh, PA) on ice with three bursts of $30 \mathrm{~s}$ each. The resultant G. duodenalis sonicates prepared from $10^{3}, 10^{5}$ and $10^{7}$ trophozoites in the volume of $0.5 \mathrm{ml}$ were added to the apical chamber of the enterocytes grown on the transwells and used as the pathogenic challenge for various time points ([Chin et al., 2002] and [Scott et al., 2002]).

Other types of $G$. duodenalis products were prepared to characterize the fraction responsible for the stimulation. Giardia duodenalis sonicates $\left(2 \times 10^{7}\right.$ trophozoites $\left./ \mathrm{ml}\right)$ in the high glucose DMEM media were either boiled at $100{ }^{\circ} \mathrm{C}$ for 5 min (termed 'boiled sonicate') or centrifuged at $12,000 \mathrm{~g}$ for $10 \mathrm{~min}$ for the collection of supernatant as the 'lysate'. Both boiled sonicate and lysate were added to the luminal surface for challenge on enterocytes for $24 \mathrm{~h}$. As another challenge preparation, the spent TYI-S33 media in which G. duodenalis was grown for 3 days was collected, cleared of whole parasites by centrifugation at $500 \mathrm{~g}$ for $10 \mathrm{~min}$, and mixed with an equal volume of the high glucose DMEM media.

\subsection{Preparation of low and high glucose media}

The apical surface of confluent Caco- 2 cells was exposed to G. duodenalis products $\left(2 \times 10^{7}\right.$ trophozoites $/ \mathrm{ml})$ in either high glucose $(25 \mathrm{mM})$ or low glucose $(5 \mathrm{mM})$ media for $24 \mathrm{~h}$ as described previously ([Yu et al., 2005] and [Yu et al., 2006]). The 'high glucose media' was purchased from Life technologies, Inc. The 'low glucose media' was made up by 1:4 ratio of high glucose DMEM and glucose-free DMEM (both from Life technologies, Inc.) and supplemented with $20 \mathrm{mM}$ of d-mannitol (Sigma) for osmotic balance. Both media were 
supplemented with $10 \%$ FBS, $15 \mathrm{mM}$ Hepes, $100 \mathrm{U} / \mathrm{ml}$ and $0.1 \mathrm{mg} / \mathrm{ml}$ Penicillin/Streptomycin, and $0.25 \mathrm{mg} / \mathrm{ml}$ Geneticin.

\subsection{Reagents}

Phloridzin is a glucose analog that has a higher affinity compared with $\alpha$-methyl glucopyranoside $(\alpha-\mathrm{MG})$ or d-glucose for binding to SGLT-1, and is used for inhibition of sugar uptake ([Kimmich and Randles, 1981] and [Turner et al., 1996]). Colchicine (a microtubule disrupting agent) or cytochalasin $\mathrm{D}$ (an actin depolymerizing agent) were used to assess the requirement of cytoskeletal proteins. The pro-apoptotic topoisomerase-I inhibitor camptothecin was used as a positive control for cell death. All of the reagents above were purchased from Sigma. The protease inhibitor cocktail complete mini ${ }^{\circledR}$ which inhibits serine, cysteine, metalloproteases and calpains, the selective cysteine protease inhibitor E64, and the selective serine protease inhibitor Pefabloc SC were purchased from Roche, Laval, Que., Canada. A non-metabolized radiolabeled sugar probe, $\mathrm{C}^{14}$-labeled $\alpha$-methyl glucopyranoside $(\alpha-M G)$, was used for the sugar uptake assay (Amersham Biosciences, Que., Canada).

\subsection{Measurement of cell apoptosis}

Caspase-3 enzymatic activity was measured in cells grown in a 24-well plate and apically exposed to G. duodenalis products for $24 \mathrm{~h}$ in low or high glucose media. Cell monolayers were lysed with $100 \mu \mathrm{l}$ of cell lysis buffer, protein concentration adjusted to $2 \mathrm{mg} / \mathrm{ml}$, and caspase-3 activity was measured at $405 \mathrm{~nm}$ wavelength according to the manufacturer's instructions (Medicorp Biosource International, Inc., Camarillo, CA). The level of caspase-3 activity was expressed as the absorbance values (O.D.) normalized to the protein amount (mg).

DNA fragmentation, which is the final stage of apoptosis, was measured using a cell death detection ELISA kit as described previously (Roche) ([Chin et al., 2002] and [Scott et al., 2002]). This quantitative sandwich enzyme immunoassay specifically measures the histone region $(\mathrm{H} 1, \mathrm{H} 2 \mathrm{~A}, \mathrm{H} 2 \mathrm{~B}, \mathrm{H} 3$ and $\mathrm{H} 4)$ of mono- or oligonucleosomes that are released during apoptosis. Enterocytes were grown in 24-well plates until confluent and exposed to $G$.

duodenalis sonicates for $24 \mathrm{~h}$. The pro-apoptotic reagent camptothecin $(20 \mu \mathrm{g} / \mathrm{ml}$ for $24 \mathrm{~h})$ was used as a positive control. The lysate of the monolayer and suspended cells were collected for the measurement of cell apoptosis. Kinetic photometric development was monitored by reading the plate at $405 \mathrm{~nm}$ at $5 \mathrm{~min}$ intervals with a THERMOmax microplate reader (Molecular Devices Corp., Menlo Park, CA). The O.D. indicative of the amount of apoptotic nucleosome was measured in duplicate, and normalized to the protein amount. The level of cell apoptosis was expressed as O.D./mg for each group.

\subsection{Trypan blue exclusion assay}

Cell viability was tested by a trypan blue exclusion assay. Cells were grown to confluence in 24-well plates and treated with phloridzin $(2 \mathrm{mM})$ in low or high glucose media for $24 \mathrm{~h}$. Briefly, monolayer was trypsinized and resuspended into single cell population with PBS. Resuspended cells were mixed in a 1:1 vol with $0.4 \%$ Trypan blue (Sigma) and the number of cells (stained and non-stained) were calculated using a hemocytometer. The level of cell viability was presented as the percentage of trypan blue-stained cells (non-viable cells) in the total cell population.

\subsection{Sugar uptake assay}

Apical surfaces of monolayers grown on transwells as above were incubated with $G$. duodenalis products in cell culture media with low or high glucose for $24 \mathrm{~h}$. Sugar uptake was measured with a radioassay using a $\mathrm{C}^{14}$-labeled sugar probe $\alpha$-MG (Amersham Biosciences, Piscataway, NJ, USA). The $\alpha$-MG sugar probe selectively binds to SGLT- 1 and is not 
transported by other glucose transporters ([Kimmich and Randles, 1981] and [Turner et al., 1996]). Preliminary studies demonstrated that $\alpha-M G$ uptake was linear from $15 \mathrm{~min}$ to at least $2 \mathrm{~h}$ in this cell culture model (Turner et al., 1996). Briefly, cells were gently washed with glucose-free Hank's balanced salt solution supplemented with $25 \mathrm{mM}$ d-mannitol (mannitolHBSS) and then incubated apically with $0.2 \mathrm{ml}$ of mannitol-HBSS containing $2 \mu \mathrm{Ci} / \mathrm{ml}(6.65$ $\mu \mathrm{M}){ }^{14} \mathrm{C}$-labeled $\alpha$-MG for $30 \mathrm{~min}$ at $37{ }^{\circ} \mathrm{C}, 5 \% \mathrm{CO}_{2}$ and $96 \%$ humidity. Cells were washed with HBSS at $4{ }^{\circ} \mathrm{C}$, solubilized with $0.1 \mathrm{~N} \mathrm{NaOH}$, and the lysate was then mixed into a Ready safe liquid scintillation cocktail (Beckman Coulter, Fullerton, CA). The level of sugar uptake was measured using a $\beta$-scintillation counter, and values expressed as nanomoles $/ \mathrm{cm}^{2}$ surface area. Selective uptake of the $\alpha$-MG sugar probe by SGLT-1 was previously established by a blockage study using $0.5 \mathrm{mM}$ phloridzin (Sigma) added in the presence of the radiolabeled probe.

For the inhibition of SGLT-1-mediated glucose uptake during the G. duodenalis challenge, various concentrations of the competing sugar phloridzin $(0,2$ and $10 \mathrm{mM})$ (Turner et al., 1996) were added to the cell culture media for $24 \mathrm{~h}$ in the presence of the G. duodenalis products. The cells were then gently washed with mannitol-HBSS, and the level of SGLT-1 activity was measured by the uptake of radiolabeled $\alpha-\mathrm{MG}$ as described above. Another set of experiments characterized the kinetics of SGLT-1 activation by calculating $K_{\mathrm{m}}$ and $V_{\max }$ of the receptor activity as described previously ([Turner et al., 1996] and [Yu et al., 2006]). GraphPad Prism software (v. 4.0, San Diego, CA) was used for the analysis of the kinetics of SGLT-1 activity.

In some experiments, to examine the role of cytoskeletal scaffolding proteins in $G$. duodenalis-induced SGLT-1 translocation, colchicine $(2.5,5$ and $10 \mu \mathrm{M})$ or cytochalasin D $(1,5$ and $10 \mu \mathrm{M})$ (Sigma) were added to the cell cultures $1 \mathrm{~h}$ prior to $\mathrm{G}$. duodenalis sonicates, and were present throughout the challenge course of $12 \mathrm{~h}$ (Yu et al., 2005). As cytoskeletal disruptors may induce apoptosis on their own ([Guo et al., 1998] and [Pollman et al., 1999]), blocking concentrations of these reagents that do not induce cell apoptosis were selected based on results from preliminary experiments, in which apoptosis was measured using a cell death ELISA (Roche). Concentrations higher than $10 \mu \mathrm{M}$ for colchicine and cytochalasin D are cytotoxic based on preliminary data of cell death.

In some experiments, a protease inhibitor cocktail (complete mini), a selective cysteine protease inhibitor (E64), or a selective serine protease inhibitor (Pefabloc, SC) (all purchased from Roche) were incubated with the prepared G. duodenalis sonicate in high glucose DMEM media at $37{ }^{\circ} \mathrm{C}$ for $5 \mathrm{~min}$, and then added to the apical surface of the cells for $12 \mathrm{~h}$. The sugar uptake level of challenged cells was subsequently measured. These protease inhibitors were added at various concentrations for dose-response experiments.

\subsection{Immunofluorescence and confocal microscopy}

Cells were grown to confluence for 1 week in an 8-well chamber slide (Lab-Tek) and exposed to G. duodenalis products for $24 \mathrm{~h}$ as previously described ([Chin et al., 2002] and [Scott et al., 2002]). Monolayers were rinsed with sterile tissue culture grade PBS, fixed with $4 \%$ paraformaldehyde for $1 \mathrm{~h}$ on ice, and quenched with $50 \mathrm{mM} \mathrm{NH}_{4} \mathrm{Cl}$ in $\mathrm{PBS}$ for $10 \mathrm{~min}$ at room temperature. After blocking with $0.1 \%$ BSA in PBS for $1 \mathrm{~h}$, monolayers were stained with primary antibodies (see below) in a permeabilizing buffer $(0.05 \%$ saponin and $0.1 \%$ BSA in PBS) for $1 \mathrm{~h}$. Cells were washed twice with $0.1 \%$ BSA-PBS, incubated with secondary antibody (see below) for $1 \mathrm{~h}$ in the dark and mounted with Aqua Poly-Mount (Polysciences, Warrington, PA). The slides were visualized on a Leica fluorescence microscope (model DMR). Micrographs were recorded with a Photometrics CoolSNAP digital camera (Roper Scientific, Tuscon, AZ). In addition, multiple image stacks and XZ-plane photomicrographs were obtained 
using a Leica TCS SP2 AOBS confocal microscope equipped with the Leica Confocal software (LCS).

For detection of SGLT-1 expression, a previously validated polyclonal rabbit anti-mouse SGLT-1 antibody that cross-reacts with human SGLT-1 (1:500, Chemicon International, Temecula, CA) was used as the primary antibody ([Chung et al., 1999] and [Chung et al., 2002a]). Secondary antibodies were goat anti-rabbit conjugated to Alexa 594 or Alexa 488 (1:1000, Molecular Probes, Eugene, OR). For detection of cell contour, phalloidin conjugated to Alexa 488 (1:40, Molecular Probes,) was used to stain for F-actin. For detection of nucleus, cells were stained with Hoechst dye $(1 \mu \mathrm{M}$, Sigma).

\subsection{Extraction of whole cell lysate and western blotting for SGLT-1}

Cells grown in 6-well plates and exposed to G. duodenalis sonicates for $24 \mathrm{~h}$ were processed for Western blotting. Briefly, cells were lysed with RIPA buffer (1\% Nonidet P-40, $0.5 \%$ sodium deoxycholate, $0.1 \%$ SDS and one tablet of complete-mini protease inhibitors cocktail (Roche) added to $10 \mathrm{ml}$ of buffer immediately before use). The lysates were centrifuged at $14,000 \mathrm{~g}$ for $10 \mathrm{~min}$ and supernatant was collected. A protein assay (BioRad Dc protein assay, BioRad, Hercules, CA) was performed, and concentrations adjusted to $5 \mathrm{mg} / \mathrm{ml}$. The supernatant was dissolved in $2 \times$ electrophoresis sample buffer containing $2 \%(\mathrm{w} / \mathrm{v})$ SDS, 100 $\mathrm{mM}$ DTT and $62.5 \mathrm{mM}$ Tris/ $\mathrm{HCl}(\mathrm{pH} 6.8)$ at a $1: 1$ ratio, and subjected to $95^{\circ} \mathrm{C}$ heat block for $5 \mathrm{~min}$ for denaturation. Samples were frozen at $-20^{\circ} \mathrm{C}$ until use for immunoblotting of SGLT-1.

Proteins in whole cell lysates were subjected to reducing SDS/PAGE (4-13\% polyacrylamide). The resolved proteins were then electroblotted onto Hybond-P hydrophobic polyvinylidene difluoride (PVDF) membranes (Amersham Biosciences). After $1 \mathrm{~h}$ blocking at room temperature in 5\% non-fat dry milk, the membranes were incubated with polyclonal rabbit anti-SGLT-1 (1:500, Chemicon International) or mouse monoclonal anti-human actin (Medicorp, Montreal, Que.) as the primary antibody overnight. Membranes were washed three times with Tris-buffered saline (TBS) with $0.1 \%$ Tween 20 for $5 \mathrm{~min}$, and incubated with secondary goat anti-rabbit or goat anti-mouse $\mathrm{IgG}$ conjugated with horseradish peroxidase (Santa Cruz Biotechnology) at room temperature for $1 \mathrm{~h}$. Antigens on the membranes were then revealed by exposure to chemiluminescent substrates (ECL plus Western blotting detection system, Amersham Biosciences, Buckinghamshire, England). Primary antibody to actin was used to control for equal loading in each sample. Precision Plus protein ${ }^{\mathrm{TM}}$ standards (BioRad) were used as molecular weight markers for protein electrophoresis.

\subsection{Statistical analysis}

All values were expressed as mean \pm standard error. Statistical significance was determined by one-way ANOVA followed by Tukey's compromise test for multiple comparisons, or paired Student's $t$-test, where appropriate. Significance was established at $P<0.05$.

\section{Results}

\subsection{Exogenous glucose inhibits G. duodenalis-induced caspase-3-dependent epithelial apoptosis}

Using the well-characterized human intestinal epithelial Caco-2 cell line, the present results confirm the pro-apoptotic effects of $G$. duodenalis in SGLT-1-transfected cells in low glucose media. Increased levels of apoptosis were demonstrated by caspase- 3 activation and DNA fragmentation upon $24 \mathrm{~h}$ exposure to G. duodenalis sonicates $\left(2 \times 10^{7}\right.$ trophozoites $\left./ \mathrm{ml}\right)$ when exogenous glucose concentration was low (Fig. 1A and B). In contrast, high glucose concentration in the culture media abolished caspase- 3 activation and DNA fragmentation 
induced by the parasitic products (Fig. 1A and B). Stimulation with camptothecin was used as a positive control for cell apoptosis (Fig. 1B).

\subsection{Exposure to G. duodenalis products increases epithelial sugar uptake in a dose- and time-dependent manner in the presence of high exogenous glucose concentration}

In an attempt to verify cellular sugar uptake level and identify the potential glucose transporter involved in these cytoprotective effects, cells were incubated with $\mathrm{C}^{14}$-labeled $\alpha$-MG (a sugar selectively transported by SGLT-1) and uptake of the radiolabeled sugar probe was quantified. Cells challenged with $G$. duodenalis sonicates $\left(2 \times 10^{7}\right.$ trophozoites $\left./ \mathrm{ml}\right)$ in a high glucose environment for $24 \mathrm{~h}$ exhibited a two-fold increase of the uptake of radiolabeled $\alpha-\mathrm{MG}$ compared with control cells. A dose-response of the epithelial sugar uptake activity was observed in cells challenged with G. duodenalis products (Fig. 2A). Cells stimulated with $G$. duodenalis sonicates $\left(2 \times 10^{7}\right.$ trophozoites $\left./ \mathrm{ml}\right)$ in high glucose media also exhibited increased sugar uptake in a time-dependent fashion (Fig. 2B). All of the subsequent challenging experiments were performed with $G$. duodenalis sonicates $\left(2 \times 10^{7}\right.$ trophozoites $\left./ \mathrm{ml}\right)$ for $24 \mathrm{~h}$ unless noted otherwise.

Additional experiments were performed to assess which fraction of $G$. duodenalis sonicates stimulates sugar uptake. Our results showed that trophozoite sonicate supernatants devoid of membranous components (lysate fraction) increased epithelial sugar uptake to the same extent as sonicates containing membranous material (Fig. 2C). Boiled sonicates or spent media failed to significantly enhance sugar uptake (Fig. 2C). Moreover, in order to assess the potential role of proteases in triggering epithelial sugar uptake, protease inhibitors were added to $G$. duodenalis sonicates prior to challenge for $12 \mathrm{~h}$. Protease inhibitor cocktails inhibited the $G$. duodenalis-induced increase of sugar uptake in a dose-dependent fashion (Fig. 3A), as did selective serine and cysteine proteases (Fig. 3B and C). These results indicated that a soluble protease fraction of $G$. duodenalis sonicates is involved in the upregulation of epithelial sugar uptake in high glucose media.

\subsection{Glucose-mediated cytoprotection against G. duodenalis-induced apoptosis is regulated by SGLT-1}

The specific role of SGLT-1 in glucose-mediated cytoprotection against $G$. duodenalis-induced apoptosis was further examined by pharmacological blockage studies using phloridzin. Phloridzin (a competitive inhibitor for glucose binding to SGLT-1) was added to high glucose media during the G. duodenalis challenge, followed by measurement of the levels of sugar uptake and cell apoptosis. Experiments first determined that phloridzin dose-dependently inhibited the increase of epithelial sugar uptake induced by G. duodenalis sonicates (Fig. 4A). Concentrations of $2 \mathrm{mM}$ phloridzin, which inhibited approximately $83 \%$ of the increment of SGLT-1-mediated sugar uptake induced by $G$. duodenalis, were selected for subsequent experiments on the modulation of cell apoptosis.

Experiments then investigated whether phloridzin may block the cytoprotective effects observed in high glucose media. The level of DNA fragmentation of G. duodenalis-exposed cells in high glucose media was significantly increased in the presence of $2 \mathrm{mM}$ phloridzin, and was comparable to that in G. duodenalis-exposed cells in low glucose environment. Therefore, the addition of phloridzin to high glucose media abolished cytoprotection (Fig. 4B). To rule out the possibility that phloridzin modified baseline levels of apoptosis or cell viability, monolayers treated with phloridzin alone were tested for DNA fragmentation and trypan blue exclusion. Our results showed that $2 \mathrm{mM}$ of phloridzin had no effect on DNA fragmentation in low or high glucose media (Fig. 4B). In addition, phloridzin did not affect cell viability (Fig. 4C). 


\subsection{Giardia duodenalis increases apical SGLT-1 expression, and increases $V_{\max }$ of the transporter}

To characterize the mechanism of increased SGLT-1 activity, SGLT-1 expression on epithelial cells was examined by immunofluorescence staining. Confocal $X Z$-plane serial imaging illustrates increased apical expression of SGLT-1 on epithelial cells following exposure to $G$. duodenalis products for $24 \mathrm{~h}$ (Fig. 5A and B). The control monolayer structure was displayed by staining with hoechst and phalloidin dyes to show the relative location of cell nucleus and cytoskeletal F-actin, respectively (Fig. 5C). To confirm this observation, further experiments determined whether the increased sugar uptake induced by $G$. duodenalis products was due to alterations in $K_{\mathrm{m}}$ (i.e., the affinity between the transporter and the sugar ligand) or $V_{\max }$ (i.e., the maximum velocity of the sugar binding) of the SGLT-1 transporter. A well-established biochemical approach, using increasing extracellular concentrations of radiolabeled sugar for SGLT-1 uptake, was used for this kinetic analysis ([Turner et al., 1996] and [Yu et al., 2006]). SGLT-1 transport in control and G. duodenalis-challenged cells was regulated by extracellular sugar concentrations in a dose-dependent pattern that fits Michaelis-Menten firstorder kinetics, where " $J=V_{\max }\left([S] /\left([S]+K_{\mathrm{m}}\right)\right)$ ". The SGLT-1 $V_{\max }$ was significantly ( 2- to 3 -fold) increased by exposure to G. duodenalis (Fig. 5D), which implies an increase in the number of transporters. No change in the affinity of SGLT-1 was observed between the control group $\left(K_{\mathrm{m}}=0.45 \mathrm{mM}\right)$ and cells challenged with $G$. duodenalis $\left(K_{\mathrm{m}}=0.41 \mathrm{mM}\right)$ (Fig. 5D). $K_{\mathrm{m}}$ values for SGLT-1 activity in control cells were consistent with previously published results (0.31 mM) (Turner et al., 1996).

In addition, the total amount of SGLT-1 protein in cell extractions was analyzed using Western blots. The total protein level of the cotransporter did not differ between control and $G$. duodenalis-challenged cells (Fig. 5E). Densitometric analysis revealed that SGLT-1 total protein levels in G. duodenalis-treated cells were $106.13 \pm 12.7 \%$, i.e., not different from control values. Taken together, the results indicate that $G$. duodenalis-stimulated increased apical expression of SGLT-1 leads to increased $V_{\max }$ of the transporter on epithelial cells, independently of alterations in total SGLT-1 protein.

\subsection{Giardia duodenalis-induced SGLT-1 activity requires an intact microtubular network}

Additional mechanistic experiments investigated whether cytoskeletal scaffolding proteins were implicated in the G. duodenalis-induced upregulation of SGLT-1 activity. Colchicine (a microtubule disrupting agent), or cytochalasin $\mathrm{D}$ (an actin depolymerizing agent) were added to the epithelial monolayers $1 \mathrm{~h}$ prior to G. duodenalis challenge, and sugar uptake was measured $12 \mathrm{~h}$ post-challenge. Colchicine blocked G. duodenalis-induced SGLT-1 activation in a dose-dependent manner (Fig. 6A), while cytochalasin D had no effect (Fig. 6B).

Preliminary experiments had established that colchicine and cytochalasin D at concentrations higher than $10 \mu \mathrm{M}$ were cytotoxic, hence such concentrations were not used in this study (Yu et al., 2005).

\section{Discussion}

A number of enteric pathogens activate epithelial apoptosis and compromise the gastrointestinal barrier function. Cytoprotective mechanisms evolved by enterocytes are at the core of gastrointestinal homeostasis and are crucial for the maintenance of an intact epithelial barrier in the face of pro-apoptotic stimuli. The present findings identify for the first time, to our knowledge, a pathway through which SGLT-1-mediated glucose uptake may protect human enterocytes against G. duodenalis-induced caspase-3-dependent apoptosis. The mechanisms include apical translocation of SGLT-1 transporters, and increased maximal rate of sugar transport $\left(\mathrm{V}_{\max }\right)$. These alterations require an intact microtubular network. 
Intestinal epithelial defects, including strain-dependent activation of apoptosis and loss of epithelial barrier function, have been implicated in the pathogenesis of giardiasis ([Chin et al., 2002], [Scott et al., 2002], [Troeger et al., 2007] and [Panaro et al., 2007]). The current study investigated potential host cytoprotective mechanisms against apoptosis induced by $G$. duodenalis. The findings confirm the direct pro-apoptotic effects of $G$. duodenalis in SGLT-1transfected human Caco-2 enterocytes grown in low glucose media $(5 \mathrm{mM})$, as evidenced by heightened caspase- 3 activity and DNA fragmentation. In contrast, in the presence of high glucose $(25 \mathrm{mM})$, G. duodenalis-induced programmed cell death was inhibited. In addition, G. duodenalis products increased epithelial uptake of an $\alpha$-MG sugar probe in high, but not in low, glucose environments. Sugar uptake was upregulated by G. duodenalis sonicates in a dose- and time-dependent manner. The addition of phloridzin, which competitively binds SGLT-1 ([Kimmich and Randles, 1981] and [Turner et al., 1996]), inhibited increased sugar uptake and, despite the presence of high glucose, allowed cellular DNA fragmentation to reach levels comparable to those measured upon exposure to G. duodenalis in low glucose. Together, these findings indicate that glucose protection against $G$. duodenalis-induced cell death is mediated by SGLT-1.

In an attempt to further characterize the parasitic fraction responsible for SGLT-1 activation, trophozoite sonicates devoid of membrane components or heat-boiled preparation, were also used as experimental challenges. Membrane-free sonicate supernatants enhanced SGLT-1 activity as effectively as complete sonicates. In contrast, boiling abolished this effect. Together, the data suggest that a soluble heat-labile protein fraction in $G$. duodenalis trophozoites triggers this SGLT-1-mediated host response. Giardia duodenalis trophozoite proteases play an important role in the microbial-host epithelial interaction during infection ([Farthing, 1993] and [Guimaraes et al., 2003]). Moreover, protease-activated receptors have been identified on intestinal epithelial cells and are involved in the regulation of cell apoptosis and inflammatory responses ([Chin et al., 2003] and [Hansen et al., 2005]). Therefore, the potential role of proteases in G. duodenalis-induced enterocytic sugar uptake was examined by the addition of various protease inhibitors to the co-cultures. Pan-protease inhibitors as well as specific serine and cysteine protease inhibitors decreased $G$. duodenalis-induced SGLT-1 activation in dosedependent fashion. The results suggest that proteases may be involved in the G. duodenalisinduced upregulation of SGLT-1-mediated sugar uptake. The potential role of proteinaseactivated receptors in this process requires further investigation.

Confocal XZ-plane imaging revealed enhanced apical expression of SGLT-1 in cells challenged with the parasitic products. Stainings of SGLT-1 on the cell surface as well as in cytoplasmic pools were observed in control cells. This observation is consistent with previously described intracellular pools containing SGLT-1 in enterocytes ([Chung et al., 2002a], [Chung et al., 2002b] and [Kipp et al., 2003]). Our findings indicate that the increased SGLT-1-specific sugar uptake triggered by exposure to G. duodenalis resulted from an augmentation of $V_{\max }$ of the cotransporter, without changes in $K_{\mathrm{m}}$. These data indicate that $G$. duodenalis increased the maximal rate of SGLT-1 sugar transport (increased surface expression of transporter), whereas the affinity between the transporter and ligand was not altered. Additional Western blot results showed that the total amount of SGLT-1 protein in epithelial cells was not increased postchallenge, suggesting that novel synthesis of the protein may not be involved in this phenomenon. Further evidence indicated that the increased expression of SGLT-1 on apical membranes of enterocytes requires intact cytoskeletal proteins and microtubules, in agreement with previous reports suggesting that intracellular compartments containing SGLT-1 are attached to microtubules (Kipp et al., 2003). In contrast, as cytochalasin D had no effect on SGLT-1 activation, actin filaments do not appear to be involved in this process. The results confirm that $G$. duodenalis-induced SGLT-1 activation is associated with enhanced apical insertion of the protein from intracellular pools via microtubules, but not through the upregulation of the total SGLT-1 protein level. 
Luminal glucose concentrations in the intestine in vivo vary, depending upon the time of the day and the segment of the gut. Free glucose concentrations in the proximal small intestinal lumen may range from zero to $48 \mathrm{mM}$ in rats fed with regular chow (Ferraris et al., 1990), whereas indirect evidence calculated from maltose absorption rates suggested glucose concentrations of 200-300 mM after a meal (Pappenheimer, 1993). The concentrations of glucose used in the present study were validated in previous studies ([Yu et al., 2005] and [Yu et al., 2006]) and are consistent with standard formulations of commercial cell culture media. Recent reports have indicated that GLUT-2 was recruited to the brush border membrane upon glucose activation of SGLT-1 via a protein kinase C-dependent pathway ([Kellett, 2001] and [Kellett and Helliwell, 2000]). However, this increase of apical GLUT-2 was not detectable until glucose concentrations reached $30-50 \mathrm{mM}$, which is close to the saturation dose for SGLT-1 binding (Kellett and Helliwell, 2000). Therefore, the high glucose concentrations used in the present studies $(25 \mathrm{mM})$ are below those needed to induce translocation of GLUT-2 to the apical membrane.

Previous reports have demonstrated that enhanced glucose uptake by SGLT-1 prevents caspase- 3 activation and cell apoptosis induced by bacterial LPS. This glucose-mediated cytoprotective phenomenon is associated with the maintenance of mitochondrial integrity, the increase of anti-apoptotic Bcl-2 and Bcl- $\mathrm{X}_{\mathrm{L}}$ expression, and the inhibition of mitochondrial cytochrome c release ([Yu et al., 2005] and [Yu et al., 2006]). A recent study utilizing microarray technology found that G. duodenalis may concurrently increase the expression of anti-apoptotic and pro-apoptotic genes in Caco-2 cells that are cultured in high glucose media (Roxstrom-Lindquist et al., 2005). Recent findings also indicate that G. duodenalis downregulates anti-apoptotic Bcl-2 and increases pro-apoptotic Bax (Panaro et al., 2007). Whether increased glucose uptake confers resistance against $G$. duodenalis-induced cell apoptosis by modifying the levels of apoptotic signaling molecules such as those belonging to the Bcl-2 family, and/or by affecting glucose metabolism and cellular energy status, represent important topics for future research.

While the observations reported here are similar to the mechanisms of SGLT-1 activation by bacterial LPS ([Yu et al., 2005] and [Yu et al., 2006]), this mechanism differs from that induced by growth factors. Indeed, epidermal growth factor translocates SGLT-1 from cytosolic pools to the epithelial brush border via actin filaments (Chung et al., 2002a). Also, our results showed that apical expression and activity of SGLT-1 were increased after 12 and $24 \mathrm{~h}$ of $G$.

duodenalis challenge, whereas the effects of epidermal growth factor occur within minutes. Using an LPS-challenge model ([Yu et al., 2005] and [Yu et al., 2006]), recent findings indicate that early apoptotic signals occur upstream of the induction of SGLT-1 translocation. This may provide an explanation for the delayed response to microbial products, versus the one to growth factors (Yu et al., 2006). More research is needed to determine whether these differences may reflect the existence of distinct epithelial signaling response pathways upon pathological versus physiological stimuli.

In summary, SGLT-1 activation may rescue enterocytes from $G$. duodenalis-induced epithelial cell apoptosis by enhancing glucose uptake. This novel host defense mechanism is characterized by increased apical expression and $V_{\max }$ of the SGLT-1 transporter, and requires an intact microtubular network. As this effect can also be observed upon exposure to bacterial LPS ([Yu et al., 2005] and [Yu et al., 2006]), more research is needed to determine whether this phenomenon represents a generic feature of the intestinal defense response against proapoptotic enteropathogens. A better understanding of this cytoprotective mechanism may help establish a rational basis for the development of therapeutic interventions in various intestinal disorders where excessive epithelial apoptosis is central to pathogenesis. 


\section{Acknowledgements}

This research was funded through a grant from the Natural Sciences and Engineering Research Council of Canada. LCH Yu was the recipient of a fellowship co-sponsored by the Canadian Association of Gastroenterology, the Canadian Institutes of Health Research, and AstraZeneca.

\section{References}

Belosevic M, Faubert GM, MacLean JD. Disaccharidase activity in the small intestine of gerbils (Meriones unguiculatus) during primary and challenge infections with Giardia lamblia. Gut 1989;30:1213-1219. [PubMed: 2806988]

Buret A, Hardin JA, Olson ME, Gall DG. Pathophysiology of small intestinal malabsorption in gerbils infected with Giardia lamblia. Gastroenterology 1992;103:506-513. [PubMed: 1634068]

Chin AC, Teoh DA, Scott KG, Meddings JB, MacNaughton WK, Buret AG. Strain-dependent induction of enterocyte apoptosis by Giardia lamblia disrupts epithelial barrier function in a caspase-3dependent manner. Infect. Immun 2002;70:3673-3680. [PubMed: 12065509]

Chin AC, Vergnolle N, MacNaughton WK, Wallace JL, Hollenberg MD, Buret AG. Proteinase-activated receptor 1 activation induces epithelial apoptosis and increases intestinal permeability. Proc. Natl. Acad. Sci. USA 2003;100:11104-11109. [PubMed: 12960392]

Chin AC, Flynn AN, Fedwick JP, Buret AG. Lipopolysaccharide disrupts epithelial tight junctional structure and function in a caspase-3-dependent fashion. Can. J. Physiol. Pharmacol 2006;84:10431050. [PubMed: 17218970]

Chung BM, Wong JK, Hardin JA, Gall DG. Role of actin in EGF-induced alterations in enterocyte SGLT1 expression. Am. J. Physiol 1999;276:G463-G469. [PubMed: 9950820]

Chung BM, Wallace LE, Hardin JA, Gall DG. The effect of epidermal growth factor on the distribution of SGLT-1 in rabbit jejunum. Can. J. Physiol. Pharmacol 2002;80:872-878. [PubMed: 12430982]

Chung BM, Wallace LE, Hardin JA, Gall DG. The effect of epidermal growth factor on the distribution of SGLT-1 in rabbit jejunum. Can. J. Physiol. Pharmacol 2002;80:872-878. [PubMed: 12430982]

Farthing MJ. Diarrhoeal disease: current concepts and future challenges pathogenesis of giardiasis. Trans. R. Soc. Trop. Med. Hyg 1993;87(Suppl 3):17-21. [PubMed: 8108843]

Ferraris RP, Yasharpour S, Lloyd KC, Mirzayan R, Diamond JM. Luminal glucose concentrations in the gut under normal conditions. Am. J. Physiol 1990;259:G822-G837. [PubMed: 2240224]

Guimaraes S, Sogayar MI, Franco MF. Protease activity in Giardia duodenalis trophozoites of axenic strains isolated from symptomatic and asymptomatic patients. Mem. Inst. Oswaldo Cruz 2003;98:7781. [PubMed: 12700865]

Guo H, Tittle TV, Allen H, Maziarz RT. Brefeldin A-mediated apoptosis requires the activation of caspases and is inhibited by Bcl-2. Exp. Cell. Res 1998;245:57-68. [PubMed: 9828101]

Hall JL, Chatham JC, Eldar-Finkelman H, Gibbons GH. Upregulation of glucose metabolism during intimal lesion formation is coupled to the inhibition of vascular smooth muscle cell apoptosis. Role of GSK3beta. Diabetes 2001;50:1171-1179. [PubMed: 11334423]

Hansen KK, Sherman PM, Cellars L, Andrade-Gordon P, Pan Z, Baruch A, Wallace JL, Vergnolle N. A major role for proteolytic activity and proteinase-activated receptor-2 in the pathogenesis of infectious colitis. Proc. Natl. Acad. Sci. USA 2005;102:8363-8368. [PubMed: 15919826]

Hediger MA, Coady MJ, Ikeda TS, Wright EM. Expression cloning and cDNA sequencing of the Na+l glucose co-transporter. Nature 1987;330:379-381. [PubMed: 2446136]

Hu Z, Wang Y, Graham WV, Su L, Musch MW, Turner JR. MAPKAPK-2 is a critical signaling intermediate in NHE3 activation following Na+ glucose cotransport. J. Biol. Chem 2006;281:2424724253. [PubMed: 16793766]

Jones NL, Islur A, Haq R, Mascarenhas M, Karmali MA, Perdue MH, Zanke BW, Sherman PM. Escherichia coli Shiga toxins induce apoptosis in epithelial cells that is regulated by the Bcl-2 family. Am. J. Physiol. Gastrointest. Liver Physiol 2000;278:G811-G819. [PubMed: 10801274]

Kellett GL. The facilitated component of intestinal glucose absorption. J. Physiol 2001;531:585-595. [PubMed: 11251042] 
Kellett GL, Helliwell PA. The diffusive component of intestinal glucose absorption is mediated by the glucose-induced recruitment of GLUT2 to the brush-border membrane. Biochem. J 2000;350:155162. [PubMed: 10926839]

Kimmich GA, Randles J. $\alpha$-Methylglucoside satisfies only $\mathrm{Na}^{+}$-dependent transport system of intestinal epithelium. Am. J. Physiol 1981;241:C227-C232. [PubMed: 7304734]

Kimmich GA, Randles J. Sodium-sugar coupling stoichiometry in chick intestinal cells. Am. J. Physiol 1984;247:C74-C82. [PubMed: 6331188]

Kipp H, Khoursandi S, Scharlau D, Kinne RK. More than apical: distribution of SGLT1 in Caco-2 cells. Am. J. Physiol. Cell. Physiol 2003;285:C737-C749. [PubMed: 12773314]

Le'Negrate G, Ricci V, Hofman V, Mograbi B, Hofman P, Rossi B. Epithelial intestinal cell apoptosis induced by Helicobacter pylori depends on expression of the cag pathogenicity island phenotype. Infect. Immun 2001;69:5001-5009. [PubMed: 11447179]

Madara JL. Maintenance of the macromolecular barrier at cell extrusion sites in intestinal epithelium: physiological rearrangement of tight junctions. J. Membr. Biol 1990;116:177-184. [PubMed: 2380981]

Malhotra R, Lin Z, Vincenz C, Brosius FC. Hypoxia induces apoptosis via two independent pathways in Jurkat cells: differential regulation by glucose. Am. J. Physiol. Cell. Physiol 2001;281:C1596C1603. [PubMed: 11600423]

Paesold G, Guiney DG, Eckmann L, Kagnoff MF. Genes in the Salmonella pathogenicity island 2 and the Salmonella virulence plasmid are essential for Salmonella-induced apoptosis in intestinal epithelial cells. Cell. Microbiol 2002;4:771-781. [PubMed: 12427099]

Panaro MA, Cianciulli A, Mitolo V, Mitolo CI, Acquafredda A, Brandonisio O, Cavallo P. Caspasedependent apoptosis of the HCT-29 epithelial cell line induced by the parasite Giardia intestinalis. FEMS Immunol. Med. Microbiol 2007;51:302-309. [PubMed: 17714487]

Pappenheimer JR. On the coupling of membrane digestion with intestinal absorption of sugars and amino acids. Am. J. Physiol 1993;265:G409-G417. [PubMed: 8214061]

Pollman MJ, Naumovski L, Gibbons GH. Endothelial cell apoptosis in capillary network remodeling. J. Cell. Physiol 1999;178:359-370. [PubMed: 9989782]

Roxstrom-Lindquist K, Ringqvist E, Palm D, Svard S. Giardia lamblia-induced changes in gene expression in differentiated Caco-2 human intestinal epithelial cells. Infect. Immun 2005;73:82048208. [PubMed: 16299316]

Savioli L, Smith H, Thompson A. Giardia and Cryptosporidium join the 'Neglected Diseases Initiative'. Trends Parasitol 2006;22:203-208. [PubMed: 16545611]

Schaffer SW, Croft CB, Solodushko V. Cardioprotective effect of chronic hyperglycemia: effect on hypoxia-induced apoptosis and necrosis. Am. J. Physiol. Hexart Circ. Physiol 2000;278:H1948H1954.

Scott KG, Logan MR, Klammer GM, Teoh DA, Buret AG. Jejunal brush border microvillous alterations in Giardia muris-infected mice: role of T lymphocytes and interleukin-6. Infect. Immun 2000;68:3412-3418. [PubMed: 10816492]

Scott KG, Meddings JB, Kirk DR, Lees-Miller SP, Buret AG. Intestinal infection with Giardia spp. reduces epithelial barrier function in a myosin light chain kinase-dependent fashion. Gastroenterology 2002;123:1179-1190. [PubMed: 12360480]

Scott KG, Yu LC, Buret AG. Role of $\mathrm{CD}^{+}$and $\mathrm{CD} 4^{+} \mathrm{T}$ lymphocytes in jejunal mucosal injury during murine giardiasis. Infect. Immun 2004;72:3536-3542. [PubMed: 15155662]

Shiue H, Musch MW, Wang Y, Chang EB, Turner JR. Akt2 phosphorylates ezrin to trigger NHE3 translocation and activation. J. Biol. Chem 2005;280:1688-1695. [PubMed: 15531580]

Slifko TR, Smith HV, Rose JB. Emerging parasite zoonoses associated with water and food. Int. J. Parasitol 2000;30:1379-1393. [PubMed: 11113263]

Teoh DA, Kamieniecki D, Pang G, Buret AG. Giardia lamblia rearranges F-actin and alpha-actinin in human colonic and duodenal monolayers and reduces transepithelial electrical resistance. J. Parasitol 2000;86:800-806. [PubMed: 10958459]

Troeger H, Epple HJ, Schneider T, Wahnschaffe U, Ullrich R, Burchard GD, et al. Effect of chronic Giardia lamblia infection on epithelial transport and barrier function in human duodenum. Gut 2007;56:328-335. [PubMed: 16935925] 
Turner JR, Lencer WI, Carlson S, Madara JL. Carboxy-terminal vesicular stomatitis virus G proteintagged intestinal $\mathrm{Na}^{+}$-dependent glucose cotransporter (SGLT1): maintenance of surface expression and global transport function with selective perturbation of transport kinetics and polarized expression. J. Biol. Chem 1996;271:7738-7744. [PubMed: 8631815]

Watson AJ, Chu S, Sieck L, Gerasimenko O, Bullen T, Campbell F, McKenna M, Rose T, Montrose MH. Epithelial barrier function in vivo is sustained despite gaps in epithelial layers. Gastroenterology 2005;129:902-912. [PubMed: 16143130]

Yu LCH, Flynn AN, Turner JR, Buret AG. SGLT-1-mediated glucose uptake protects intestinal epithelial cells against LPS-induced apoptosis and barrier defects: a novel cellular rescue mechanism? FASEB J 2005;19:1822-1835. [PubMed: 16260652]

Yu LC, Turner JR, Buret AG. LPS/CD14 activation triggers SGLT-1-mediated glucose uptake and cell rescue in intestinal epithelial cells via early apoptotic signals upstream of caspase-3. Exp. Cell Res 2006;312:3276-3286. [PubMed: 16860318] 

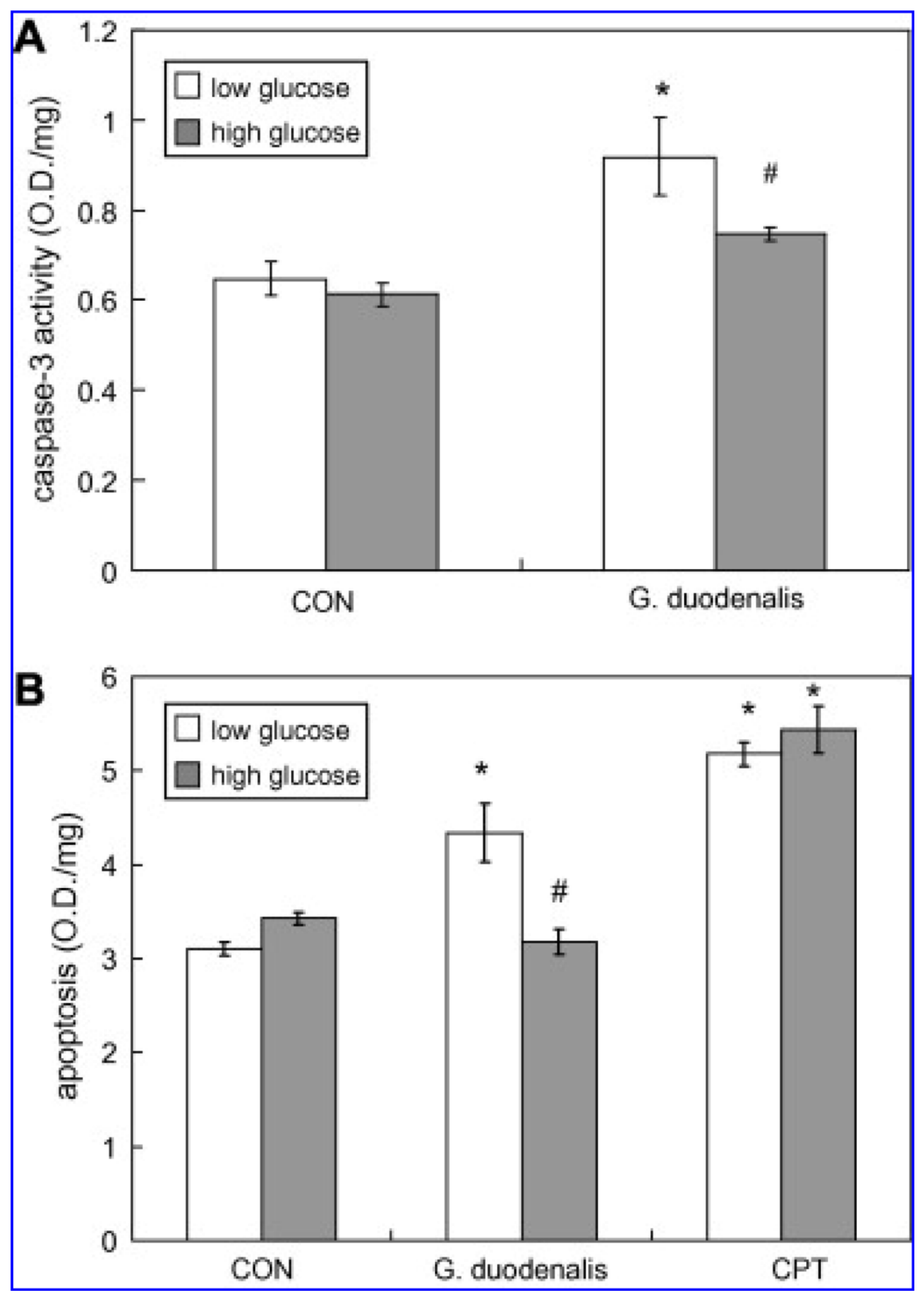

Fig. 1.

Giardia duodenalis products induce caspase-3-dependent apoptosis in intestinal epithelial cells in low, but not high, glucose media. (A) Caspase-3 activity is significantly increased in epithelial cells exposed to $2 \times 10^{7}$ trophozoites $/ \mathrm{ml}$ of G. duodenalis sonicate in low glucose media $(5 \mathrm{mM})$ for $24 \mathrm{~h}$ compared with those of controls $(\mathrm{CON})$. The presence of high glucose $(25 \mathrm{mM})$ inhibited the caspase-3 activation. (B) In low glucose media, levels of DNA fragmentation are significantly increased in cells exposed to G. duodenalis $\left(2 \times 10^{7}\right.$ trophozoites $/ \mathrm{ml}$ ) compared with those of controls $(\mathrm{CON})$. This increase is abolished in the presence of high glucose. The amount of DNA fragmentation was detected using an ELISAbased method. The pro-apoptotic camptothecin (CPT) $(20 \mu \mathrm{g} / \mathrm{ml}$ for $24 \mathrm{~h})$ was used as a positive 
control. $n=6$ 6roup. ${ }^{*} P<0.05$ compared with controls. ${ }^{\#} P<0.05$ compared with cells challenged with $G$. duodenalis in low glucose media. 

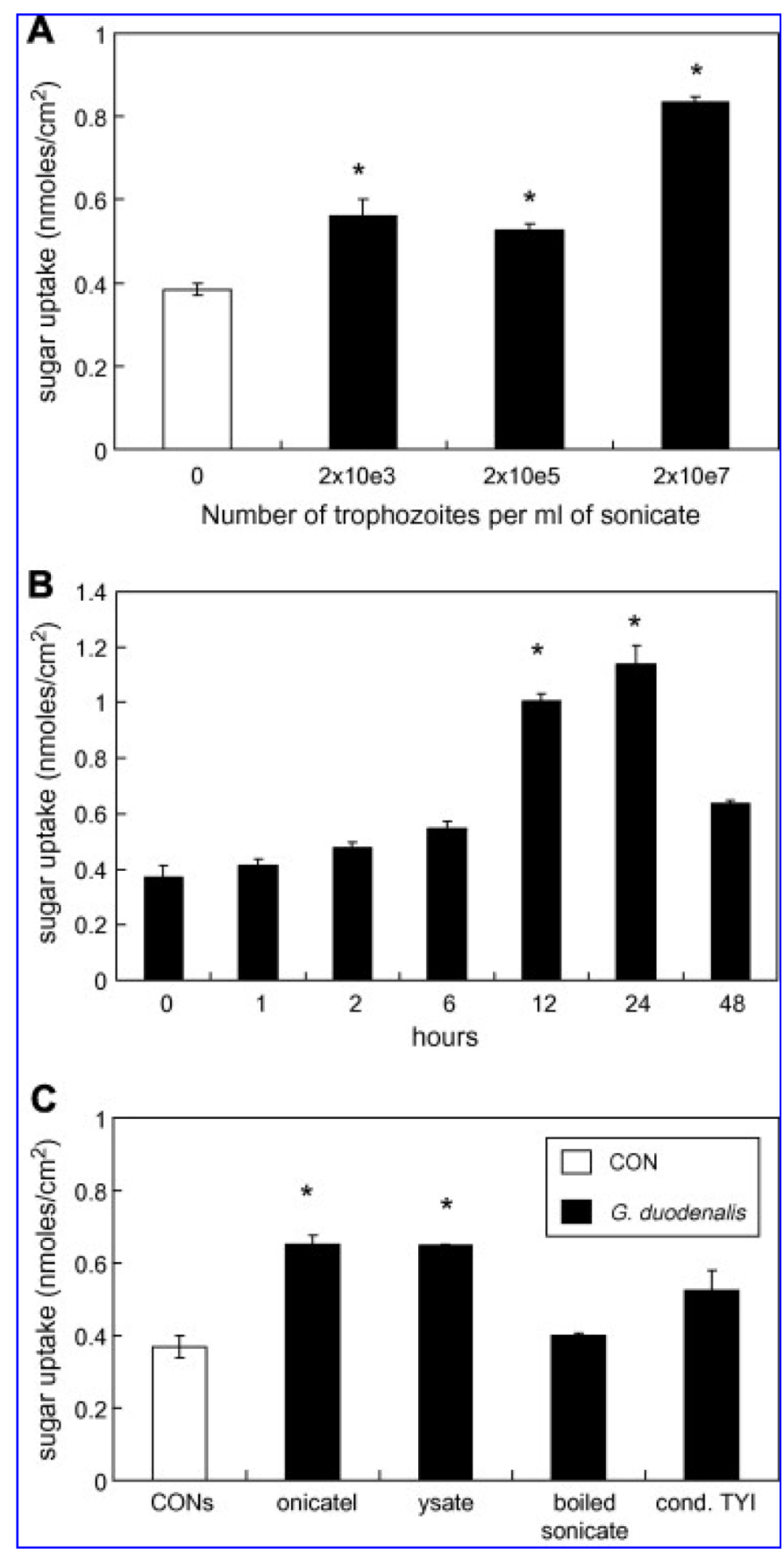

Fig. 2.

Characterization of Giardia duodenalis-induced epithelial sugar uptake in human intestinal epithelial cells in high glucose media. (A) Giardia duodenalis products enhanced cellular sugar uptake in a dose-dependent manner. The dosage of $G$. duodenalis products is presented as the number of trophozoites used for the preparation of sonicates to challenge cells for 24 h. $n=3$ / group. * $P<0.05$ compared with " 0 " control. (B) Giardia duodenalis products induced increased sugar uptake in a time-dependent fashion. The dosage of $G$. duodenalis products was $2 \times 10^{7}$ trophozoites $/ \mathrm{ml}$ of sonicates. $n=3$ /group. $* P<0.05$ compared with " 0 " control. (C) Giardia duodenalis sonicates, as well as sonicate supernatants (lysate), but not heat-boiled sonicates or conditioned growth media (cond. TYI) stimulate epithelial sugar uptake compared 
to untreated controls (CON). The challenge dose of G. duodenalis sonicates was $2 \times 10^{7}$ trophozoites/ml for 24 h. $n=3$ /group. $* P<0.05$ compared with controls. 

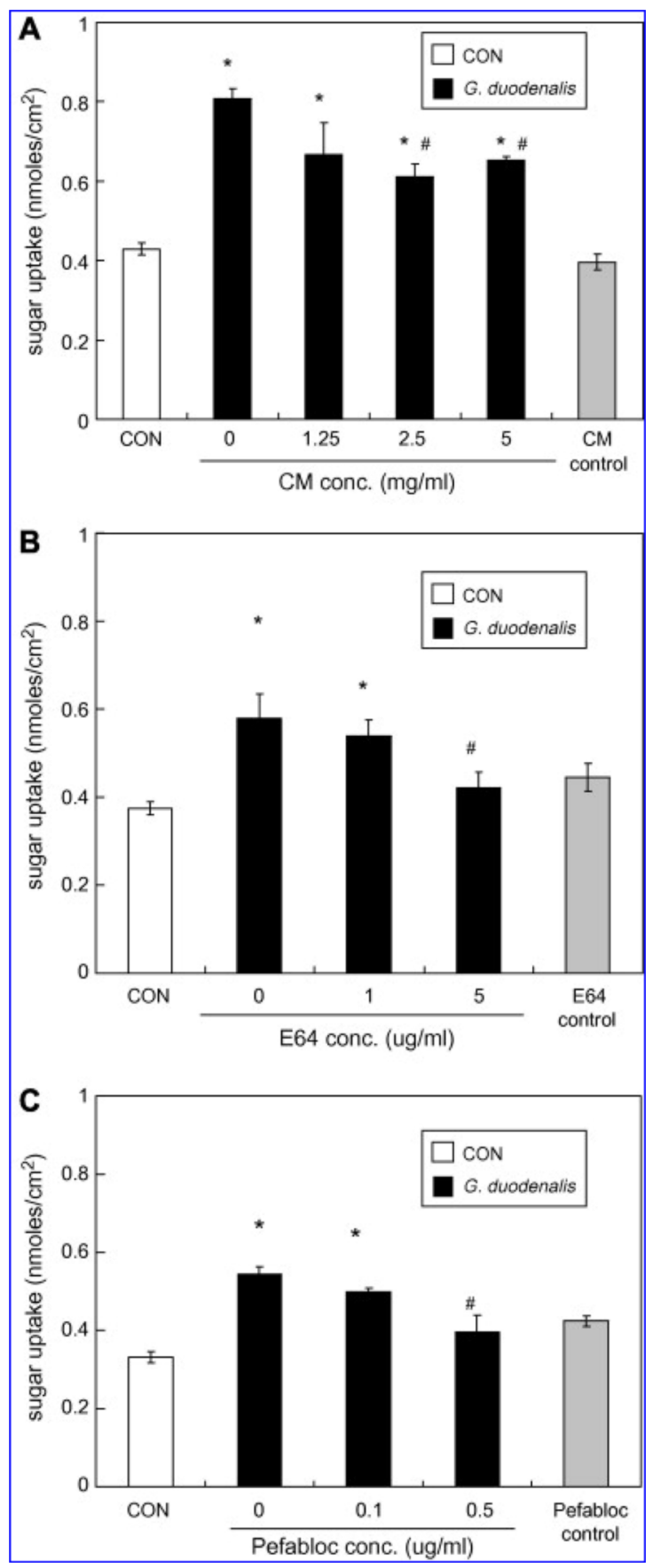

Fig. 3.

Giardia duodenalis-induced increase of epithelial sugar uptake is mediated by proteases. (A) Addition of protease inhibitor cocktails, complete mini (CM) decreased G. duodenalisenhanced sugar uptake. CM alone (CM control) had no effect on baseline enterocytic sugar uptake. $n=3$ /group. ${ }^{*} P<0.05$ compared with untreated controls $(\mathrm{CON}) .{ }^{\#} P<0.05$ compared with G. duodenalis exposure without CM. (B and C) The selective cysteine protease inhibitor E64, as well as the selective serine protease inhibitor Pefabloc, blocked G. duodenalis-induced sodium-dependent glucose cotransporter-1 activation in a dose-dependent manner. E64 alone (E64 control), or Pefabloc alone (Pefabloc control), did not alter baseline sugar uptake. $n=3$ / 
group. $* P<0.05$ compared with untreated controls (CON). ${ }^{\#} P<0.05$ compared with $G$. duodenalis exposure without E64 or Pefabloc. 


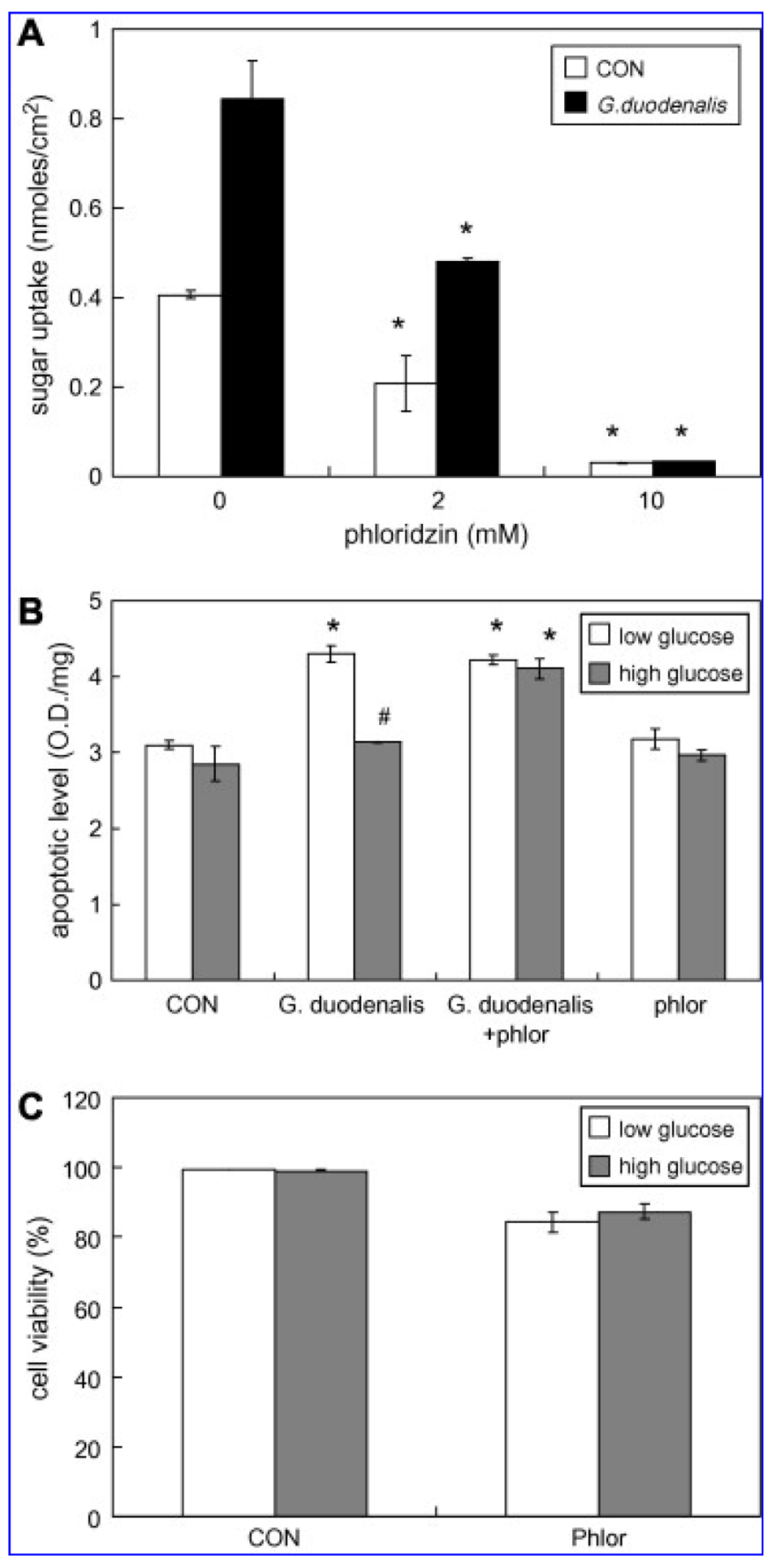

Fig. 4.

Phloridzin inhibits the enhanced sodium-dependent glucose cotransporter (SGLT)-1-mediated sugar uptake and cytoprotection against Giardia duodenalis-induced cell apoptosis. (A) Administration of phloridzin dose-dependently inhibits SGLT-1-mediated sugar uptake induced by $G$. duodenalis sonicates in high glucose conditions. Cells challenged with $G$. duodenalis sonicates are represented by black bars, whereas control $(\mathrm{CON})$ cells are represented by white bars. $n=3$ /group. ${ }^{*} P<0.05$ compared with cells exposed to $G$. duodenalis in the absence of phloridzin (“0”). (B) Phloridzin (phlor) at $2 \mathrm{mM}$ inhibits the glucose-mediated protection of human intestinal epithelial cells against $G$. duodenalis-induced apoptotic DNA fragmentation. $n=3$ /group. ${ }^{*} P<0.05$ compared with respective controls 
(CON) in low or high glucose media. ${ }^{\#} P<0.05$ compared with the $G$. duodenalis-exposed group in low glucose conditions. Phloridzin alone does not alter apoptotic levels. (C) Phloridzin alone $(2 \mathrm{mM}, 24 \mathrm{~h})$ does not affect the percentage (\%) of viable cells in low or high glucose media compared with untreated controls (CON), as assessed by trypan blue exclusion assay. $n=8$ group. 


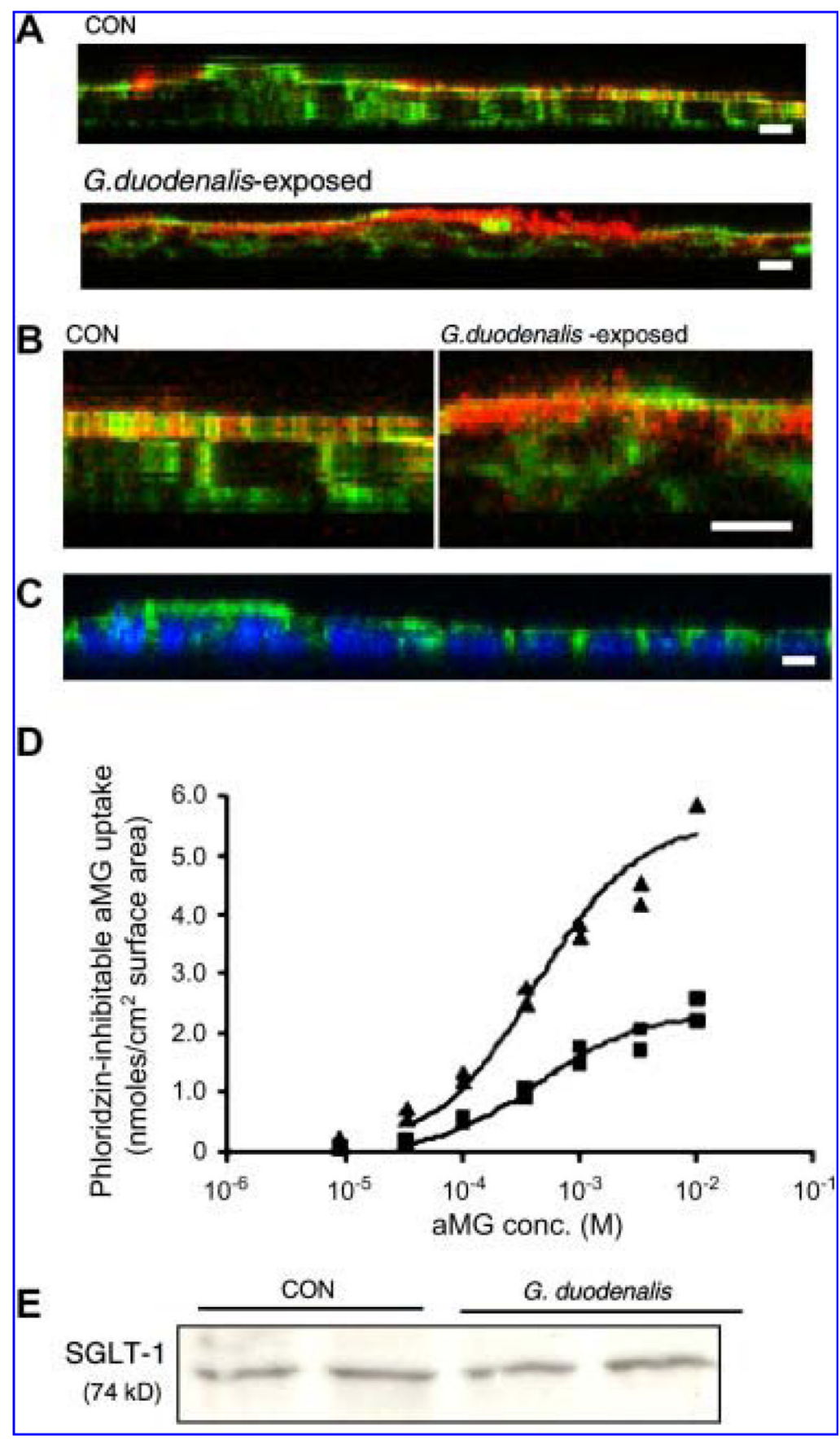

Fig. 5.

Giardia duodenalis products augmented the apical expression of sodium-dependent glucose cotransporter (SGLT)-1, and results in a two-fold increase of maximum sugar transport activity. (A) Confocal XZ-plane serial imaging illustrates the increased expression of SGLT-1 (red) on the apical surface of human intestinal epithelia cells exposed to G. duodenalis ( $24 \mathrm{~h}$ ) compared with controls $(\mathrm{CON})$. Cell silhouettes are identified by actin staining using phalloidinconjugated fluorescence (green color). Representative images obtained from three individual experiments. Bar $=10 \mu \mathrm{m}$. (B) At higher magnification, the expression of SGLT-1 (red staining) can be visualized at the brush border membrane. Cell contour is shown by F-actin staining (green color). Bar $=10 \mu \mathrm{m}$. (C) Relative subcellular location of nucleus and F-actin 
on the control epithelial monolayer was displayed by staining with Hoechst (blue color) and phalloidin (green color). Bar $=10 \mu \mathrm{m}$. (D) First-order kinetics of sugar transport in Caco-2 cells transfected with SGLT-1. The increased SGLT-1 activity induced by $G$. duodenalis results from an enhanced $V_{\max }$ without change in $K_{\mathrm{m}}$. The SGLT-1 $V_{\max }$ was significantly increased ( 2-to 3-fold) by exposure to G. duodenalis ( $\boldsymbol{\Lambda})$ compared with that of controls ( $(\boldsymbol{)})$. No change in the affinity of SGLT-1 was observed between the control group $\left(K_{\mathrm{m}}=0.45 \mathrm{mM}\right)$ and cells challenged with $G$. duodenalis $\left(K_{\mathrm{m}}=0.41 \mathrm{mM}\right)$. Each point represents an individual measurement of $\alpha$-methyl glucopyranoside ( $\alpha$-MG) sugar uptake after the subtraction of mean non-specific sugar uptake, i.e., phloridzin-independent uptake. Data were fitted to MichaelisMenten first order kinetics. (E) Western blotting images of SGLT-1 in cellular protein extracts. Total SGLT-1 levels are not different between untreated control cells (CON) and cells exposed to G. duodenalis products for $24 \mathrm{~h}$. Samples were loaded in duplicate for electrophoresis. Images are representative of three separate experiments. 

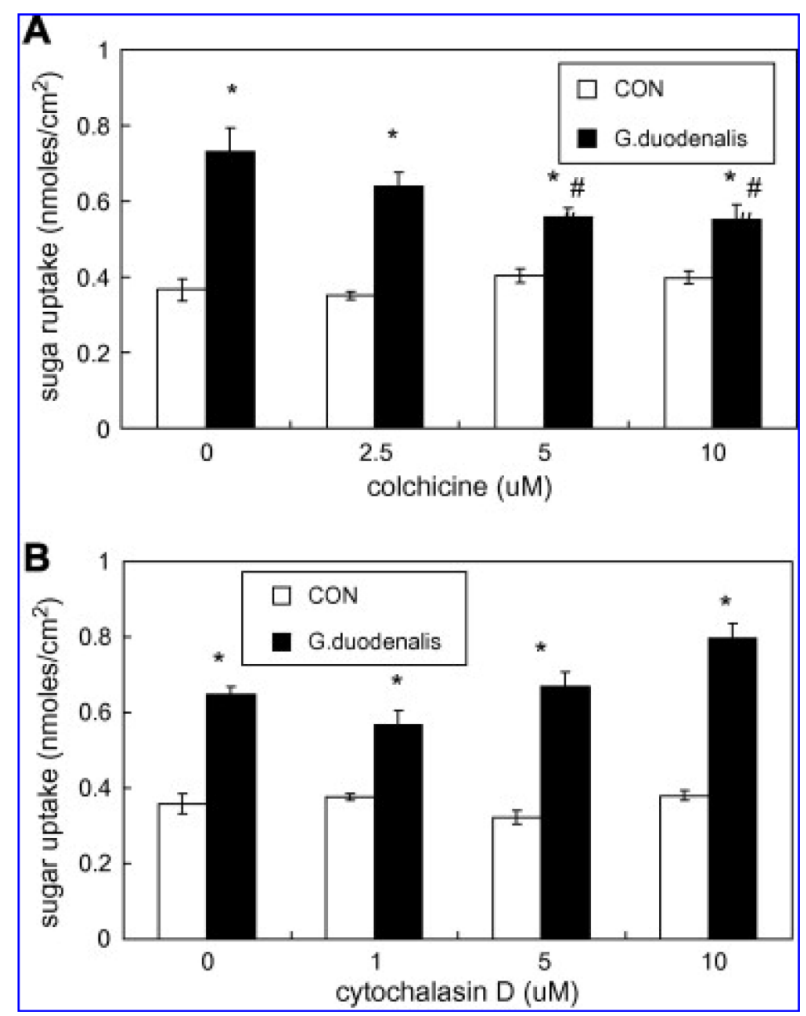

Fig. 6.

Giardia duodenalis-induced sodium-dependent glucose cotransporter-1 activation requires an intact microtubular network. (A) The microtubule disrupting agent colchicine dosedependently attenuates $G$. duodenalis-induced sugar uptake. (B) Pretreatment with cytochalasin D, which blocks actin polymerization, had no effect on the G. duodenalis-induced increase in sugar uptake. Both agents were added to the cell culture $1 \mathrm{~h}$ prior to $G$.

duodenalis sonicates and were present throughout the challenge course of $12 \mathrm{~h}$. $n=3$ /group. $* P<0.05$ compared with controls $(\mathrm{CON})$. 